\title{
Relato de experiência do projeto integrador no desenvolvimento do software para gerenciar feiras de alimentos do Município de Iporá
}

\author{
Experience report from an integrated project developing a street food market managing software \\ in Iporá \\ Informe de experiencia del proyecto integrador en desarrollo de software para la gestión de ferias \\ alimentarias en el Municipio de Iporá
}

Recebido: 17/12/2020 | Revisado: 18/12/2020 | Aceito: 02/01/2021 | Publicado: 05/01/2021

\author{
Filipe Jesus Portilho \\ ORCID: https://orcid.org/0000-0003-0854-8911 \\ Instituto Federal de Educação, Ciência e Tecnologia Goiano, Brasil \\ E-mail: filipe.portilho@estudante.ifgoiano.edu.br \\ Eliana Tiba Gomes Grande \\ ORCID: https://orcid.org/0000-0003-1501-7967 \\ Instituto Federal de Educação, Ciência e Tecnologia Goiano, Brasil \\ E-mail: eliana.tiba@ifgoiano.edu.br \\ Kellyanny Chaves Lima \\ ORCID: https://orcid.org/0000-0003-4259-6730 \\ Instituto Federal de Educação, Ciência e Tecnologia Goiano, Brasil \\ E-mail: kellyannylima@hotmail.com \\ Lucas Venâncio Bernardo Costa Leite \\ ORCID: https://orcid.org/0000-0002-8912-4696 \\ Instituto Federal de Educação, Ciência e Tecnologia Goiano, Brasil \\ E-mail: luccasvenancio@outlook.com
}

\begin{abstract}
Resumo
Pensar em currículo integrado é pensar em integração de experiências e conhecimentos enriquecedores, através da prática pedagógica assistida, planejamento coletivo, criação de projetos integradores, programas de iniciação científica e de extensão, projetos de pesquisa, práticas profissionais integradas, entre outras práticas inovadoras utilizadas para o alcance dos objetivos do curso. Este projeto integrador é sobre o desenvolvimento de um software para gerenciar as feiras de alimentos do município de Iporá-GO. O objetivo é desenvolver um aplicativo que facilite a vida das pessoas que tem o costume de frequentar as feiras de alimentos, mostrando as bancas com seus devidos produtos, a sua origem e o valor, bem como melhorar a relação entre consumidores e a agricultura familiar. No primeiro momento, levantou-se as feiras realizadas na cidade de Iporá e o perfil dos comerciantes. No segundo momento, fez a análise do sistema com os dados levantados. No terceiro e último momento, desenvolveu o aplicativo na linguagem Delphi com banco de dados SQlite. O aplicativo mostrou-se que atende ao problema proposto e está de acordo com os conceitos do UX.
\end{abstract}

Palavras-chave: Currículo integrado; Software; Comércio local; Produtos orgânicos; Informação.

\begin{abstract}
Thinking about an integrated curriculum is equivalent to think about combining enriching experience and knowledge throughout assisted pedagogical practice, collective planning, integrative projects creation, undergraduate and extension research as well as research projects and integrated professional practices. These are some of the groundbreaker practices used in order to achieve the goals set for one course. This integrative project concerns the development of a software that aims to manage a local food street market in Iporá, state of Goiás, by creating a mobile application that can ease the life of street market's costumers by showing them the stands and its products along with their source and price, as well as improve the costumer-family farmers relationship. At first, a survey containing the food street markets that takes place in Iporá and the merchants' profile was made, then the surveyed data were analyzed. And finally, the software was developed using Delphi computer language along with the database SQlite, and it was revealed that the application serves its purpose and is, by all means, according to the UX concepts.
\end{abstract}

Keywords: Integrated curriculum; Software; Local business; Organic products; Information.

\section{Resumen}

Pensar en un currículo integrado equivale a pensar en combinar experiencias y conocimientos enriquecedores a través de la práctica pedagógica asistida, la planificación colectiva, la creación de proyectos integradores, la investigación de grado y extensión, así como proyectos de investigación y prácticas profesionales integradas. Estas son algunas de las 
prácticas pioneras que se utilizan para lograr los objetivos establecidos para un curso. Este proyecto integrador se refiere al desarrollo de un software que tiene como objetivo la gestión de un mercadillo de comida local en Iporá, estado de Goiás, mediante la creación de una aplicación móvil que pueda facilitar la vida de los clientes del mercadillo mostrándoles los stands y sus productos junto con sus fuente y precio, así como mejorar la relación clienteagricultor familiar. En un primer momento se realizó una encuesta con los mercadillos de comida que se realizan en Iporá y el perfil de los comerciantes, luego se analizaron los datos relevados. Y finalmente, el software se desarrolló utilizando el lenguaje informático Delphi junto con la base de datos SQlite, y se reveló que la aplicación cumple su propósito y está, por supuesto, de acuerdo con los conceptos de UX.

Palabras clave: Plan de estudios integrado; Software; Negocio local; Productos orgánicos; Información.

\section{Introdução}

A feira livre é uma manifestação da cultura urbana brasileira que se mantém viva apesar do crescente avanço do desenvolvimento do comércio e da facilidade do consumidor em ter acesso a hipermercados/sacolões e a compras virtuais (Internet), com um conforto e comodidade, que inclui o horário flexível e até mesmo facilidades de pagamento. Assim, percebe-se que essas feiras acontecem em pequenas e grandes cidades, seja na periferia ou em bairros nobres (Santos, 2017).

Assim sendo, o intuito das feiras é dar oportunidade para que as pessoas possam comprar mercadorias provenientes da agricultura familiar, com foco em produtos orgânicos, além de possibilita a geração de renda dos produtores. Diversas pessoas não têm disponibilidade de ir as feiras, que geralmente acontece em um dia específico da semana. Vale ressaltar ainda, que em algumas regiões as feiras se tornaram uma tração turística, pela quantidade de elementos contidos nela (Silveira, 2017).

Durante a história das feiras características marcantes ficaram, como por exemplo o grito, que é muito utilizado para os feirantes realizarem a propaganda de seus produtos. No contexto econômico, social e cultural, estes eventos tem grande relevância, uma vez que possibilita um maior giro na economia, produção de empregos e de boa parte do PIB (produto Interno Produto) brasileiro, gerando por consequência uma série de avanços tecnológicos, afim de elevar a produtividade.

A maior da parte dos integrantes das feiras livres vem da agricultura familiar, que são atividades que utilizam mão de obra da própria família, e boa parte da renda familiar é proveniente das atividades agropecuárias desenvolvidas no meio rural de sua propriedade.

É importante destacar que a venda de produtos nesse método de comercialização não é fácil, já que se deve observar vários aspectos para definir o preço dos produtos, para que o comerciante não sofra prejuízo com o preço muito baixo, e também não venda seus produtos com preço muito elevado, perdendo bastante vendas e levando os seus produtos de volta para casa. A realização da ação de voltar com produtos para casa é sinônimo de que os produtos estavam com preço alto ou outro fator, o que é frustrante para certos feirantes.

Um fator super importante a ser observado nas feiras é a segurança do local, limpeza das bancas, variedade dos produtos, qualidade dos produtos, preços dos produtos, horários das feiras, estrutura das feiras, atendimentos dos feirantes, disponibilidade dos produtos e o contato direto com os produtores que fornecem os produtos. Esses fatores são importantes, pois os clientes não se sentem à vontade em locais que não possuem essas características.

Nesse contexto, o objetivo do projeto foi o desenvolvimento de um software que apresentasse as informações sobre as feiras de alimentos do município de Iporá, sua localização e os produtos vendidos em cada uma delas, como forma de facilitar a busca por produtos oriundos da agricultura familiar.

O levantamento e a resolução deste problema foi através do PI (Projeto Integrador) do curso Técnica em Desenvolvimento de Sistemas Integrado ao Ensino Médio do IF Goiano - Campus Iporá. O Projeto Integrador é uma proposta de trabalho interdisciplinar que tem como objetivo integrar/inter-relacionar os conhecimentos nas áreas específicas e de conhecimentos gerais, promovendo o desenvolvimento de competências, a capacidade pessoal de pesquisar, mobilizar, articular e colocar em ação conhecimentos, habilidades, atitudes e valores, contribuindo para a formação integral do estudante.

Sendo assim, os Projetos Integradores devem ser realizados de forma integrada entre, pelo menos, duas disciplinas: 
uma disciplina do núcleo básico e uma do núcleo articulador ou profissional. As disciplinas envolvidas neste projeto integrador foram: Linguagem de Programação, Análise de Sistemas e Biologia.

A matriz curricular do curso técnico em desenvolvimento de sistemas integrado ao ensino médio do IF Goiano Campus Iporá segue o padrão integrador, no qual os diferentes eixos integram-se para o alcance do perfil profissional definido, bem como, do alcance dos objetivos geral e específicos estabelecidos.

A presença do Núcleo Articulador, na matriz curricular, intenciona a criação de um espaço onde a integração curricular pode ser alcançada através da articulação dos conteúdos propostos nos componentes curriculares com o uso de ferramentas e metodologias.

Considerando que a base teórica da proposta de currículo integrado está fundamentada na pesquisa e na investigação como princípio pedagógico, além de integrar os saberes e conhecimentos das diferentes áreas do conhecimento através de projetos integradores, oportunizando aos educandos têm de sintetizar e aplicar os conceitos trabalhados em sala de aula, a avaliação da aprendizagem é entendida, nesta proposta, como um instrumento permanente do trabalho docente e como parte integrante do processo ensino aprendizagem. Deve ser entendida ainda, como um processo contínuo que sirva à permanente orientação da prática docente e como uma ferramenta para alcançar o principal objetivo da escola que é permitir os estudantes avançar em seus estudos, propiciando a reflexão sobre o nível de qualidade do trabalho escolar, tanto do aluno quanto do professor, gerando mudanças significativas no decorrer do processo de formação.

\section{Tecnologia na Sociedade e Comércio}

Com o crescimento da população, e consequentemente o surgimento de novas ideias, a tecnologia ganhou espaço na sociedade, sendo bastante utilizada desde as pessoas mais novas, até aquelas que moram longe dos grandes centros urbanos, dando origem a um processo de equidade, e melhoria dos padrões de vida das comunidades, em escala mundial (Korn, 2015).

A circunstância, a ser observada, é que a modernização vem ganhando o espaço de vastas áreas da comunidade, desde as conversas habituais até a venda de produtos sem a interação cliente-vendedor. Isso é efeito constante das evoluções na sociedade, que cada vez possibilita aumentarmos a relação com pessoas e serviços sem sair da comodidade e de sua residência.

O fruto dessa ação, gera um fluxo maior de informações, já que podemos acessar o que queremos de qualquer lugar e de diversas formas, evitando deslocamentos que gerem gastos desnecessários. Para isso muitas empresas e instituições de ensino estão realizando a produção de softwares, com intuito de facilitar a humanidade em suas ações cotidianas.

Isso deve ao fato de nos últimos anos os utensílios utilizados continuamente pelas famílias, terem alavancado o preço, ocasionando o filtro dos mesmos, afim de buscar certos produtos com o melhor custo.

A não aderência dessa ideia pode gerar consequências drásticas para vida comercial do empresário, visto que as negociações estão concorridas, saindo melhor o que busca ideias inovadoras (Priscilla,2017).

Desta forma, a todo momento surgem novas ideias para nos ajudar nesta causa, e uma dessas ideias foi a criação desse software para ajudar na busca de produtos oriundos da agricultura familiar, e com um preço acessível para ser usufruído, aliado concepção de economizar.

\section{COVID-19}

Em decorrência da covid-19, as feiras do município de Iporá tiveram que mudar a maneira de comercializar os seus produtos, e para isso foram utilizadas diversas estratégias, uma vez que as feiras são locais onde existem muitas aglomerações, por apresentarem conteúdo/produtos de uso constante na sociedade.

Segundo o decreto no 360 de 11 de Setembro de 2020 da Prefeitura de Iporá, é possível elencar as seguintes estratégias exigidas pela prefeitura de Iporá, que são: a exigência de uma quantidade máxima de pessoas por banca, a disponibilidade de 
álcool 70\% por parte dos feirantes, a higienização pessoal e de utensílios como, mesas, balcões, maquinas de cartão, cadeiras e etc.

\subsection{Produtos comercializados nas feiras livres de Iporá - Goiás}

Os dados aqui apresentados foram obtidos através de entrevista realizada aos feirantes. Não foi realizado uma análise química dos produtos comprovando que são livres de qualquer resíduo químico (agrotóxicos), fertilizantes sintéticos ou processados com ionização ou aditivos. De acordo com dados estatísticos levantados através da pesquisa com cerca de 20 feirantes, foi possível observar a origem dos produtos.

Em relação a existência e venda de produtos orgânicos, foi possível observar que cerca $57 \%$ dos feirantes comercializa produtos de origem orgânica, enquanto cerca de 38\% apresenta seus produtos de origem inorgânica, e outros 5\% desconhecem a origem. Isso simboliza, que a maioria dos feirantes produzem seus próprios produtos visualizado no Gráfico 1.

Gráfico 1 - Origem dos produtos - Orgânicos e Inorgânicos.

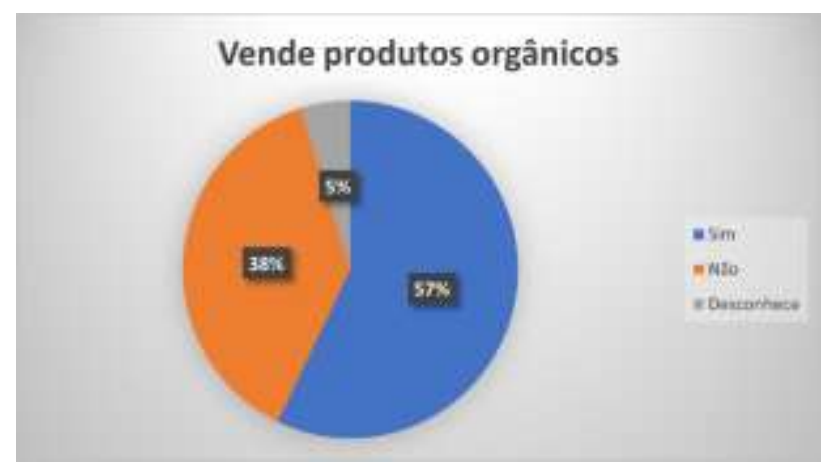

Fonte: Autores (2020).

Já em relação a origem dos produtos, foi possível observar que a maioria é de origem própria, representando cerca de 43\%, além de apresentar produtos de terceiros, o que exemplifica cerca de 38\% da origem, e outros $19 \%$ apresentam produtos de origem própria e de terceiros (Gráfico 2).

Gráfico 2 - Origem dos produtos - Próprio ou de terceiros.

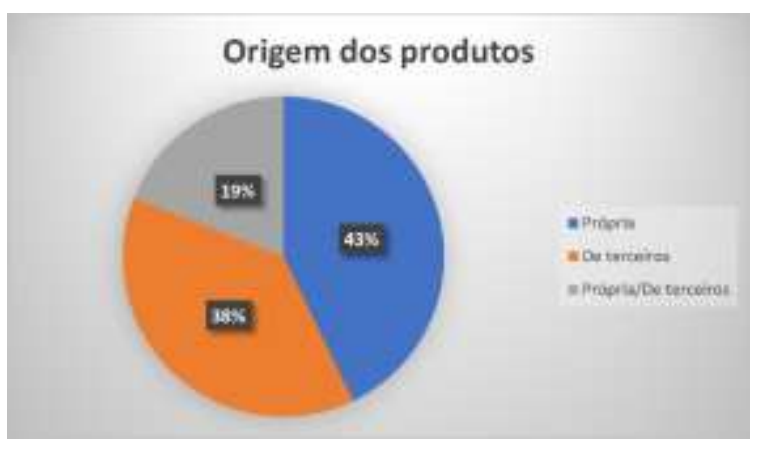

Fonte: Autores (2020).

Em relação ao número de produtos vendidos de terceiros, é possível verificar que boa parte deles é proveniente de Centros de Distribuição como o CEASA de Goiânia, que representa cerca de 37\%, ou até mesmo de grandes produtores da região do entorno de Iporá, que representa cerca de $27 \%$, e outros $36 \%$ apresenta feirantes com produtos do CEASA e da região (Gráfico 3). 
Research, Society and Development, v. 10, n. 1, e12810111283, 2021

(CC BY 4.0) | ISSN 2525-3409 | DOI: http://dx.doi.org/10.33448/rsd-v10i1.11283

Gráfico 3 - Origem dos produtos - Locais.

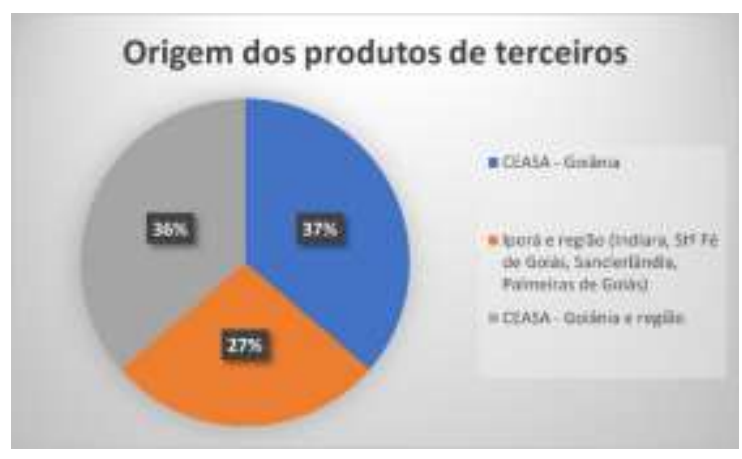

Fonte: Autores (2020).

Logo, abaixo segue algumas fotos representativas do dia a dia (Imagens 1, 2, 3, 4 e 5) das feiras do município de Iporá nos dias de sábado e Domingo seguindo o Decreto nº 360 (Iporá, 2020).

Figura 1 - Clientes participando da Feira de Domingo no Município de Iporá.

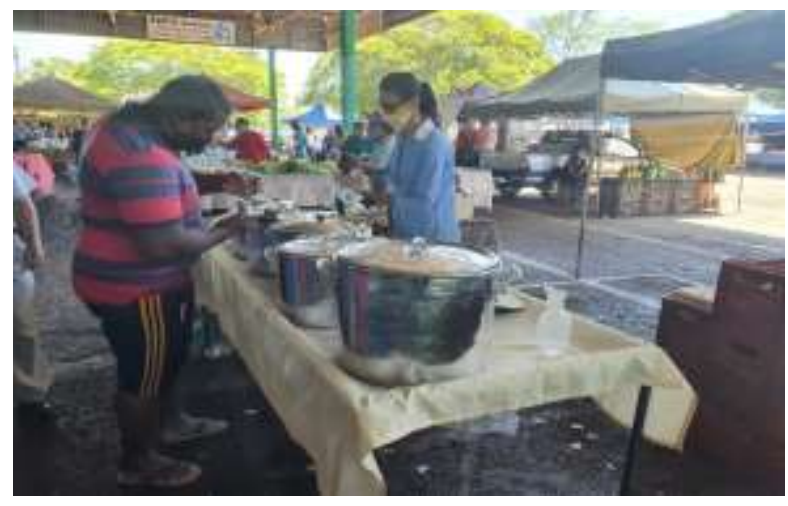

Fonte: Autores (2020).

Figura 2 - Feirante com seus produtos participando da Feira de Domingo no Município de Iporá.

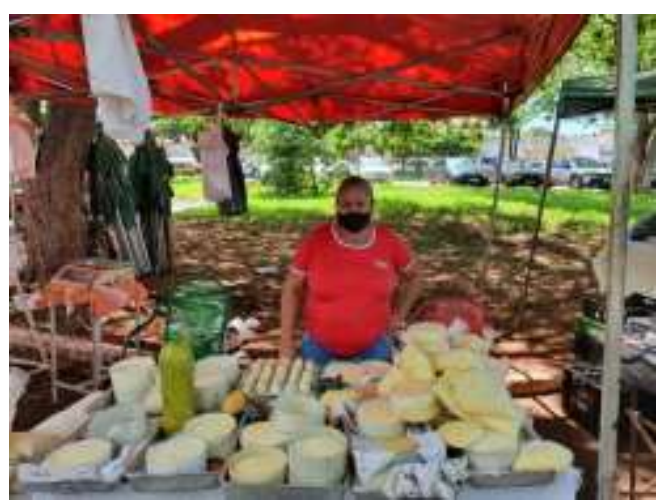

Fonte: Autores (2020). 
Figura 3 - Venda de hortaliças na Feira de Domingo no Município de Iporá

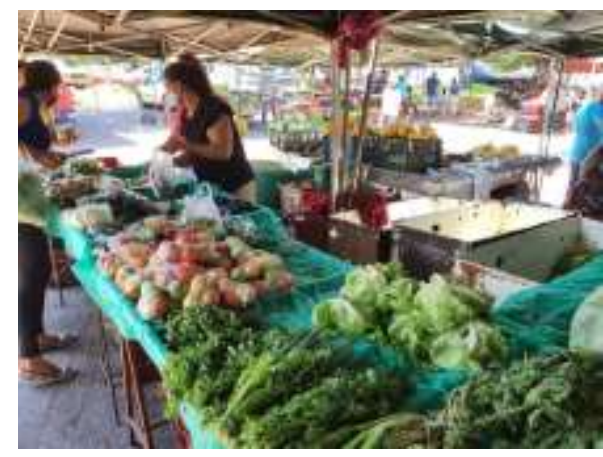

Fonte: Autores (2020).

Figura 4 - Produtos da Feira de Sábado no Município de Iporá.

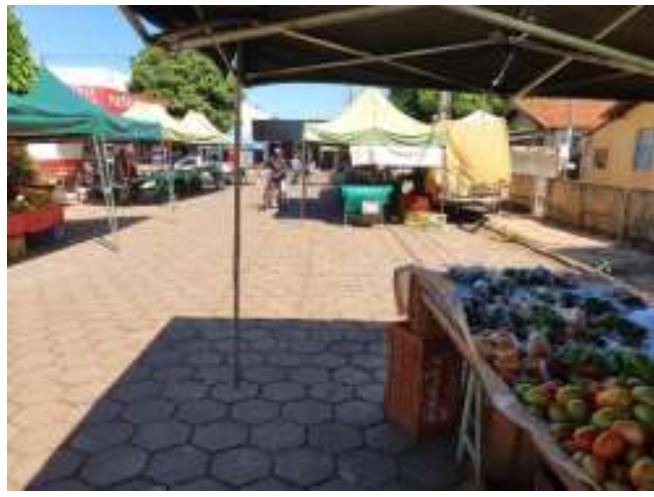

Fonte: Autores (2020).

Figura 5 - Feirante com seus produtos participando da Feira de Sábado no Município de Iporá.

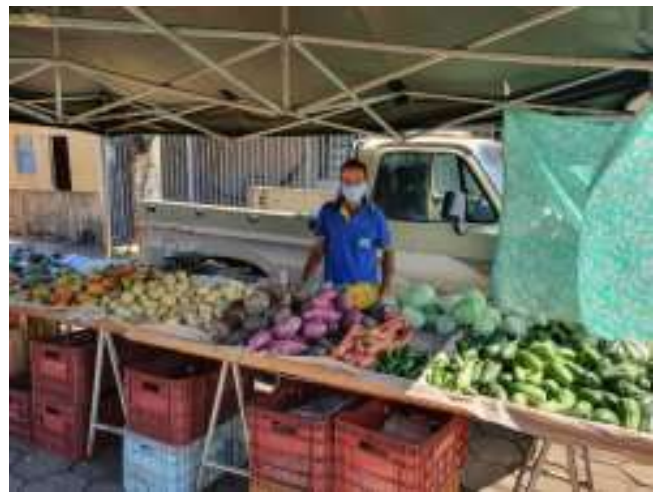

Fonte: Autores (2020).

\section{Material e Métodos}

O trabalho realizado utilizou como base uma pesquisa em campo, afim de obter informações especificas sobre o assunto, com objetivo de produzir informações para contribuir com a pesquisa de forma descritiva. Assim, estas informações contribuem para enriquecimento do trabalho (Pereira, et. al., 2018).

Depois disso, partimos para a parte pratica que é aplicação destes dados dentro da atividade a ser realizada, para verificarmos as reais condições, e executarmos o projeto com a produção do software. 
O software tem a participação dos usuários com a função de escolher uma das feiras disponíveis para ter acesso aos produtos à disposição em cada uma delas, a localização e o preço dos produtos.

Para o desenvolvimento desse software, inicialmente foi necessário realizar um levantamento sobre as informações referentes às feiras da cidade.

Além disso, foi preciso utilizar uma linguagem de programação para criar uma série de instruções, afim de permitir um programador escrever um conjunto de ordens, ações consecutivas, dados e algoritmos para criar programas para controlar o comportamento físico e lógico de uma máquina (Duarte, 2015).

Baseado nisso, foi realizado a modelagem do software, utilizando as instruções do livro Aprenda UML por meio de estudos de casos, de Wilson Moraes Góes. Logo após, isso foi realizado a produção da parte de códigos do software (Góes, 2017).

Utilizando a plataforma RAD Studio 10.3, responsável por realizar programas em código, foi possível realizar a produção do aplicativo para dispositivos móveis, através da linguagem de programação Delphi muito utilizado no desenvolvimento de aplicações desktop, aplicações multicamadas e cliente/servidor, compatível com os bancos de dados mais conhecidos do mercado (Kalmykov, 2017).

Assim, para realizar a armazenagem de dados foi utilizado o Banco de Dados o SQLite, que é uma biblioteca em linguagem $\mathrm{C}$ que implementa um banco de dados SQL embutido, sendo responsável por ler arquivos informados pelo usuário no projeto realizado pelo Delphi e escrever diretamente no arquivo de banco de dados no disco. De acordo com Hipp, o SQLite é mais vantajoso pelo fato da sua simplicidade, em implementar e administrar a implementação dos dados, além de não necessitar de um sistema SGBD (Sistema Gerenciador de Banco de Dados), para ter acesso a aplicação de dados.

Pensando nisso, percebe-se essa ideia no artigo SQLite para Dispositivos Móveis, que apresenta instruções para melhorar o desempenho desta ferramenta no aplicativo Android, para que o software ocupe pouca memória no sistema (Silva, 2017).

Figura 6 - Diagrama de Caso de Uso.

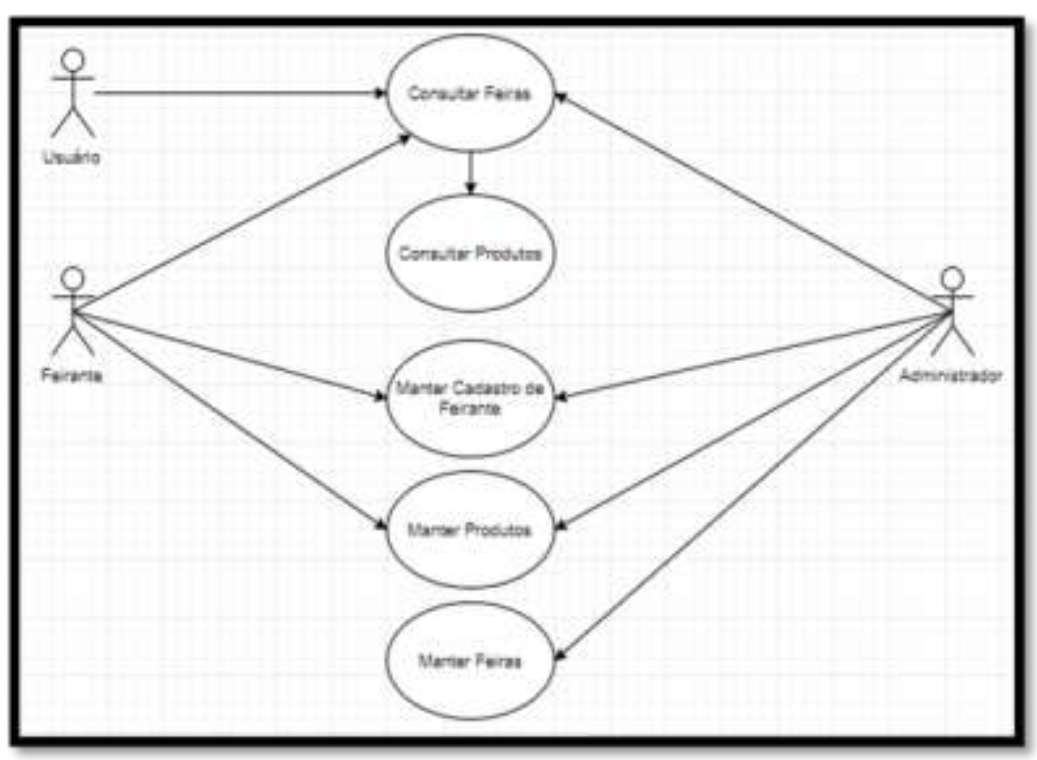

Fonte: Autores (2020). 
Desta forma, espera-se divulgar o trabalho dos comerciantes das feiras, que geralmente não tem acesso a marketing, e da mesma maneira informar a população sobre as feiras e seus respectivos horários, bem como os produtos disponíveis em cada uma delas.

Como segue na Figura 6, é possível perceber que o software tem 3 atores principais, que são:

- Administrador: responsável por realizar o cadastro dos feirantes, das feiras, os horários, os endereços e alterar ou excluir as informações de cada uma das feiras visualizada na figura 8 após entrar na área restrita do sistema (Figura 10).

- Feirante: tem acesso às informações das feiras do município de Iporá e ao selecionar a feira desejada serão fornecidas informações do endereço, horários e os produtos disponíveis na feira selecionada (Figura 8). Além disso, poderá criar e alterar seu cadastro no sistema (Figura 11), pode incluindo, alterar ou excluir a sua banca na feira (Figura 12), o os seus produtos comercializados (Figura 13).

- Usuário/Cliente: tem acesso às informações das feiras do município de Iporá e ao selecionar a feira desejada serão fornecidas informações do endereço, horários e os produtos disponíveis na feira selecionada (Figura 8). Todos os usuários podem visualizarem informações sobre o sistema (Figura 9).

Como mostra na Figura 7, é a tela principal comum para todos os usuários supracitados anteriormente. Nela pode-se fazer o login caso seja feirante ou administrador. Pode-se pesquisar sobre as feiras da semana e seus produtos e conhecer um pouco sobre o projeto clicando o terceiro.

Figura 7 - Tela de principal da Feira Livre Online.

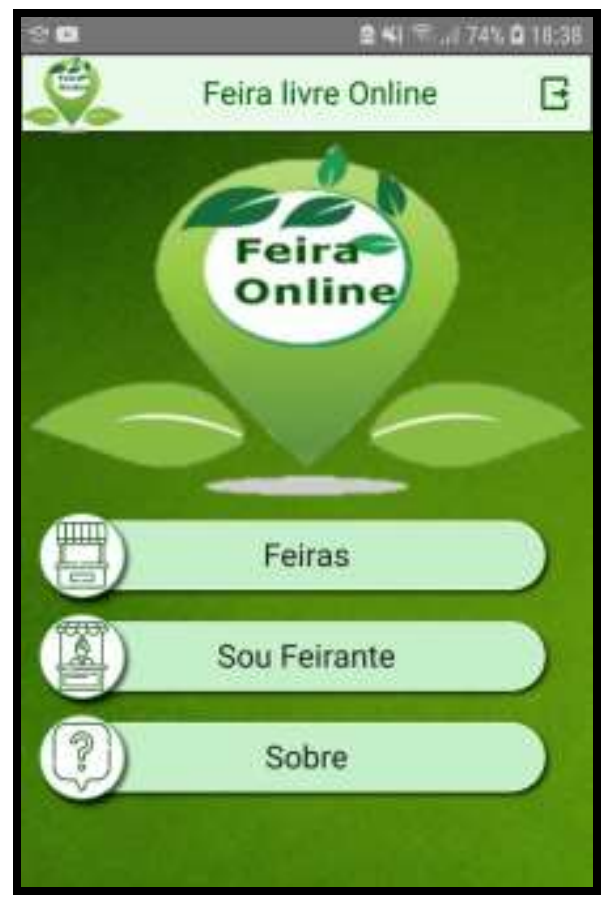

Fonte: Autores (2020). 
Research, Society and Development, v. 10, n. 1, e12810111283, 2021

(CC BY 4.0) | ISSN 2525-3409 | DOI: http://dx.doi.org/10.33448/rsd-v10i1.11283

Figura 8 - Consulta dos dados das Feiras.

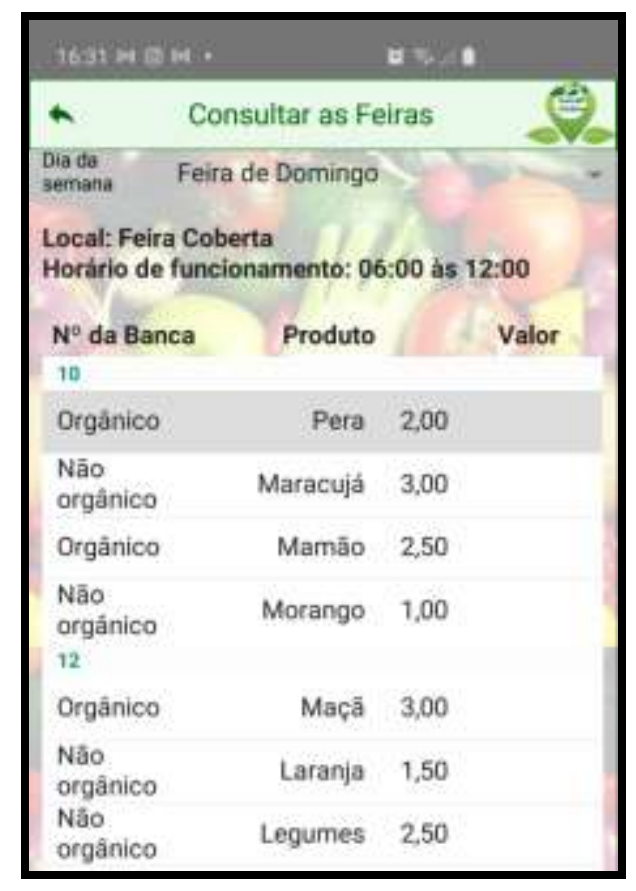

Fonte: Autores (2020).

Figura 9 - Informações sobre o aplicativo.

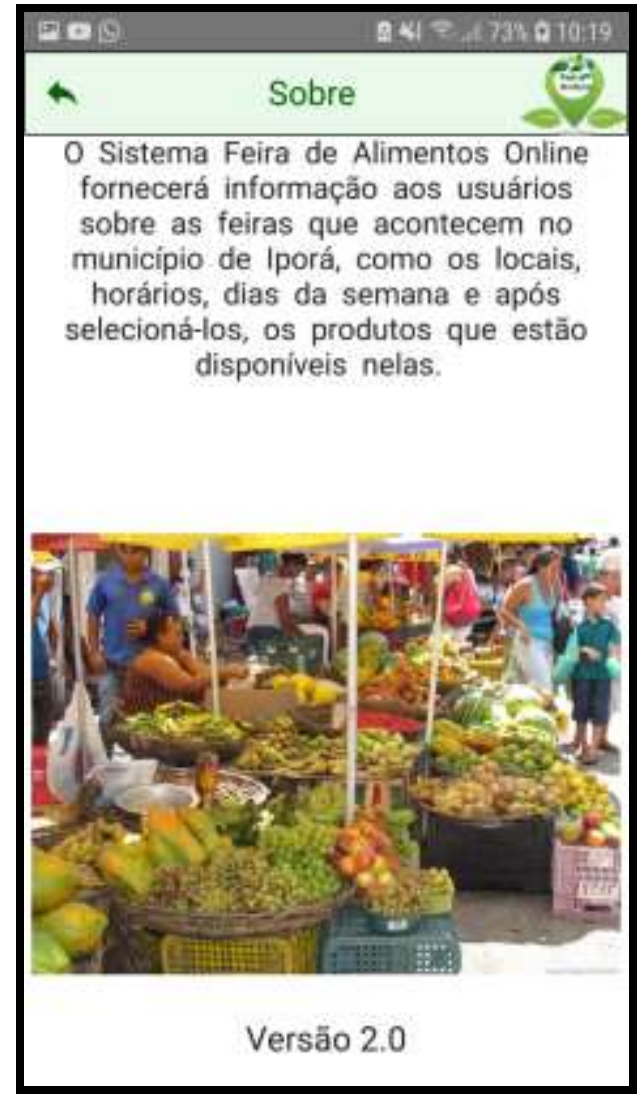

Fonte: Autores (2020). 
Research, Society and Development, v. 10, n. 1, e12810111283, 2021

(CC BY 4.0) | ISSN 2525-3409 | DOI: http://dx.doi.org/10.33448/rsd-v10i1.11283

Figura 10 - Tela de Login do aplicativo.

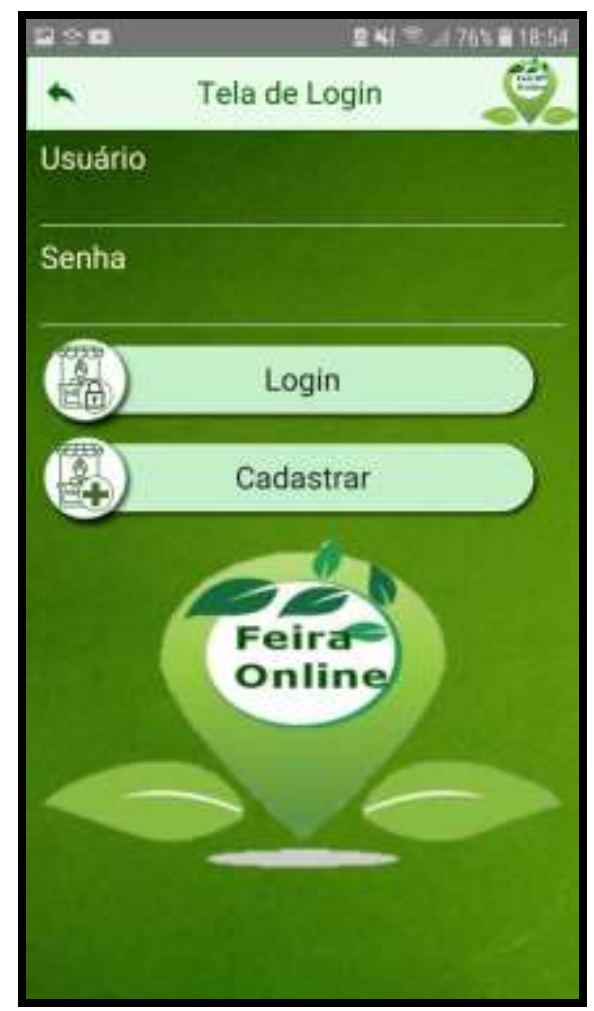

Fonte: Autores (2020).

Figura 11 - Tela menu do Feirante.

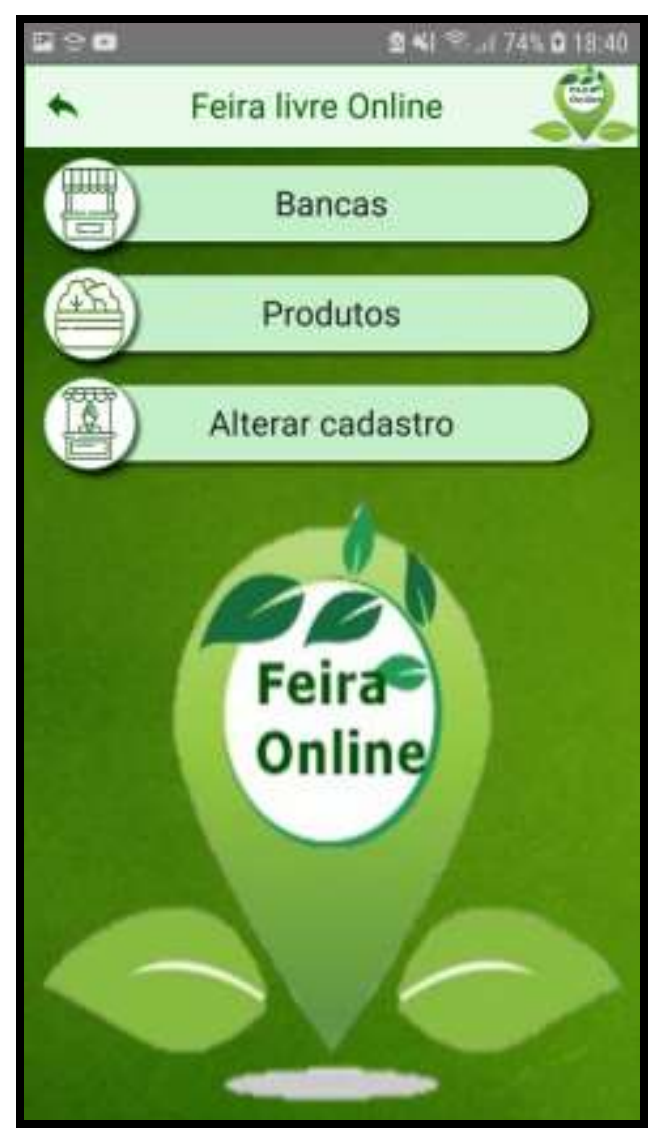

Fonte: Autores (2020). 
Research, Society and Development, v. 10, n. 1, e12810111283, 2021

(CC BY 4.0) | ISSN 2525-3409 | DOI: http://dx.doi.org/10.33448/rsd-v10i1.11283

Figura 12 - Consulta de Bancas do Feirante.

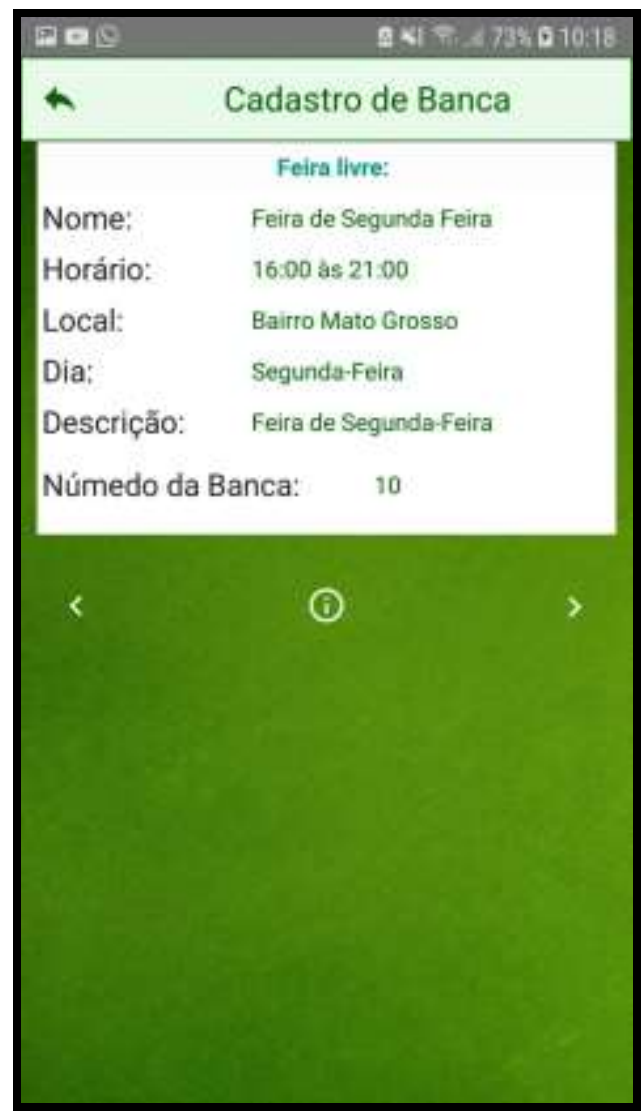

Fonte: Autores (2020).

Figura 13 - Consulta produtos comercializados pelo feirante.

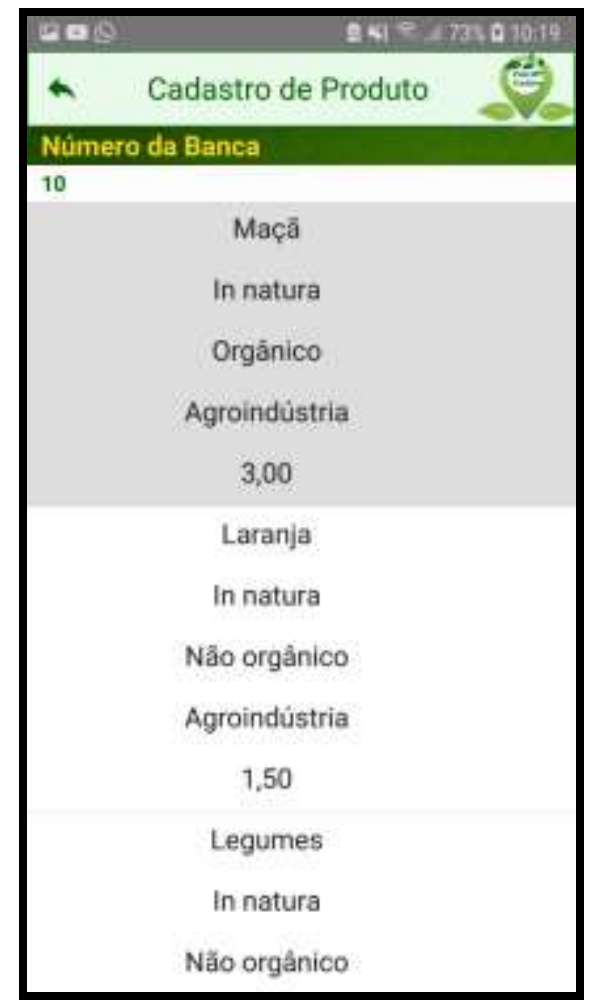

Fonte: Autores (2020). 


\section{Resultados e Discussões}

Considerando que a base teórica da proposta de currículo integrado está fundamentada na pesquisa e na investigação como princípio pedagógico, além de integrar os saberes e conhecimentos das diferentes áreas do conhecimento através de projetos integradores, oportunizando aos educandos têm de sintetizar e aplicar os conceitos trabalhados em sala de aula, a avaliação da aprendizagem é entendida, nesta proposta, como um instrumento permanente do trabalho docente e como parte integrante do processo ensino aprendizagem.

Deve ser entendida ainda, como um processo contínuo que sirva à permanente orientação da prática docente e como uma ferramenta para alcançar o principal objetivo da escola que é permitir os estudantes avançar em seus estudos, propiciando a reflexão sobre o nível de qualidade do trabalho escolar, tanto do aluno quanto do professor, gerando mudanças significativas no decorrer do processo de formação.

Desta forma, o sistema apresentado atende ao propósito que foi criado de acordo com os relatos dos feirantes e espera-se expandir o trabalho dos produtores locais, que geralmente não tem acesso e nem conhecimento sobre marketing. Além disso, almeja-se informar a população sobre as feiras e seus respectivos horários, bem como os produtos disponíveis em cada uma delas.

\section{Considerações Finais}

Dentre os conceitos integradores/geradores do eixo-tecnológico, do curso técnico e das áreas do ensino médio, discriminados a partir do Perfil do Egresso, identifica-se em cada componente curricular, quais conceitos estão mais presentes nele e podem ser mais explorados pelas caraterísticas da área de conhecimento deste componente curricular.

Tais conceitos serão favoráveis para garantir a integração e construção dialética das práticas pedagógicas, identificando as situações problemas da realidade do estudante e, a partir das quais, o docente poderá nortear suas práticas, de forma integrada com outras áreas de atuação.

Portanto, espera-se que através desse software, auxilie os feirantes com o objetivo de criar novas alternativas para evoluir seu trabalho dentro deste ramo, afim de reduzir a estratificação da sociedade comercial. Outro ponto importante é ajudar a comunidade local a encontrar informações sobre as feiras e seus produtos facilitando o seu dia a dia.

Além disso, os próximos trabalhos relacionados ao assunto, tem por objetivo a aprimorar o software, com a atualização e implementação de novas informações, afim de ajudar os usuários com informes reais.

\section{Referências}

Aplicações mestre-detalhe com FireDAC. (2017). https://www.devmedia.com.br/aplicacoes-mestre-detalhe-com-firedac/38087.

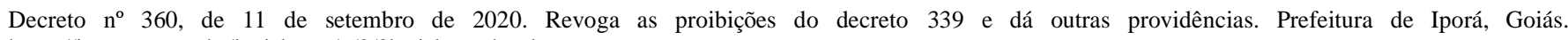
https://ipora.go.gov.br/legislacao/p/2/?legislacao.html.

Duarte, W. (2015). Delphi para Android e iOS: Desenvolvendo Aplicativos Móveis. Embarcadero.

Godoy, W., \& Anjos, F. (2007). A Importância Das Feiras Livres Ecológicas: Um Espaço De Trocas E Saberes Da Economia Local. Cadernos De Agroecologia, 2(1). http://revistas.aba-agroecologia.org.br/index.php/cad/article/view/1943.

Góes, W. (2014). Aprenda UML por meio de estudos de casos. Editora Novatec.

Groot, E. \& Groot, L. S. (2017). Importância dos atributos de uma feira livre ideal em Cassilândia, estado do Mato Grosso Do Sul: uso do Experimento de Escolha Discreta Melhor - Pior. Instituto de Economia Agrícola (IEA). http://www.iea.sp.gov.br/out/LerTexto.php?codTexto=14326.

Hipp, D. O que é SQLite. https://www.portalgsti.com.br/sqlite/sobre/.

Kalmykov, Y. (2017). Programação Em Delphi Para Iniciantes. Editora Embarcadero.

Korn, D. (2015). A tecnologia a serviço da comunidade. https://www.revista-uno.com.br/numero-20/a-tecnologia-a-servico-da-comunidade. 
Research, Society and Development, v. 10, n. 1, e12810111283, 2021 (CC BY 4.0) | ISSN 2525-3409 | DOI: http://dx.doi.org/10.33448/rsd-v10i1.11283

Pereira, A., Shitsuka, D., Parreira, F., Shitsuka, R. (2018). Metodologia da pesquisa científica. UAB/NTE/UFSM. https://repositorio.ufsm.br/bitstream/handle/1/15824/Lic_Computacao_Metodologia-Pesquisa-Cientifica.pdf?sequence=1 .

Qual a importância da tecnologia no seu comércio? (2017). https://blog.sebrae-sc.com.br/qual-importancia-da-tecnologia-no-seu-comercio/.

Santos, J. (2017). Feira livres: suas origens e relações de consumo. https://meuartigo.brasilescola.uol.com.br/administracao/feiras-livres-suas-origens-relacoesconsumo.htm

Silva, P., Schantz, D., Antunes, R., Schuch, $\quad$ R. $\quad$ SQLite $\quad$ para $\quad$ Dispositivos https://pdfs.semanticscholar.org/ba61/5e89577281fad7129e12c5277a5823617bba.pdf.

Silveira, V., Oliveira, E., Silveira, N., Mariani, M. (2017). Avaliação da importância das feiras livres e a forma de comercialização adotada pelos feirantes na cidade de Nova Andradina - MS. Anais do I Encontro Internacional de Gestão, Desenvolvimento e Inovação (EIGEDIN), 1. http://docplayer.com.br/80249632-Avaliacao-da-importancia-das-feiras-livres-e-a-forma-de-comercializacao-adotada-pelos-feirantes-na-cidade-de-novaandradina-ms.html 